\title{
Transoral endoscopic surgical resection of a giant pedunculated polyp
}

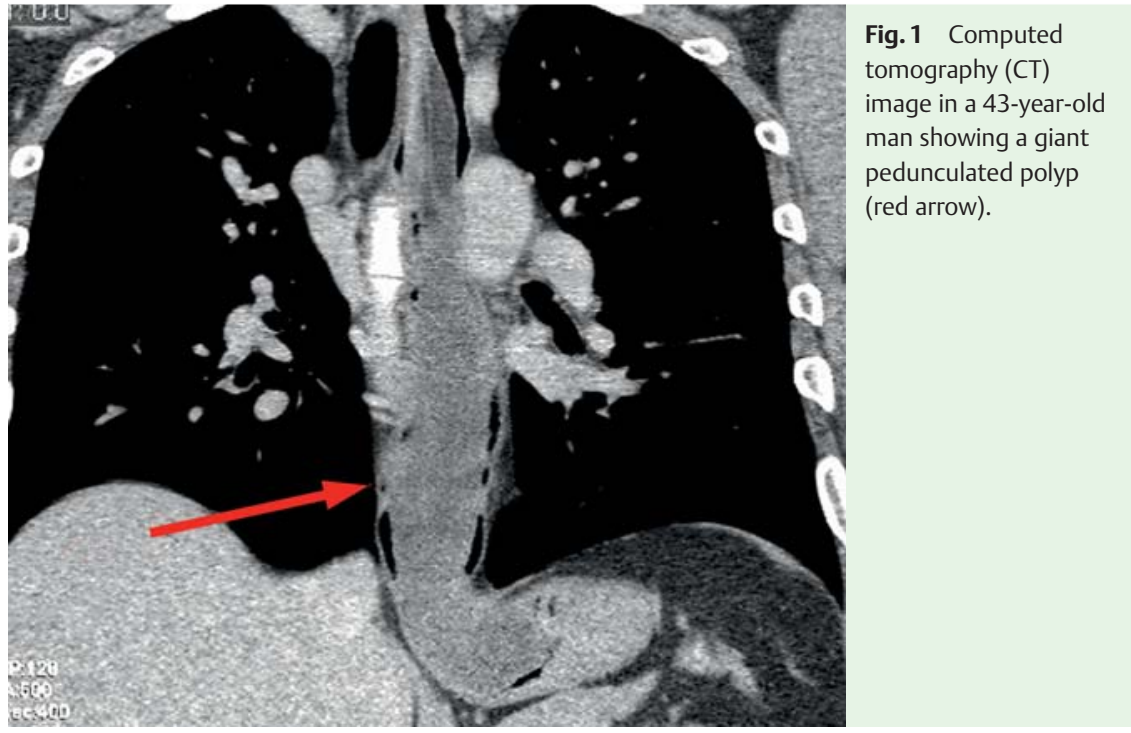

Large pedunculated fibrovascular polyps are uncommon, mostly benign, intraluminal masses, which are usually located in the upper esophageal tract [1]. The most frequently reported clinical manifestation is dysphagia, followed by regurgitation, chest pain, and intestinal bleeding. Computed tomography (CT) scanning and magnetic resonance imaging (MRI) are key in the diagnostic work-up, revealing a sausage-shaped intraluminal mass. Endoscopy with ultrasonography and biopsy add important information for the diagnosis and pedicle location.

Surgical excision is deemed appropriate because of the potentially life-threatening complication of airway obstruction [2]. Polyp resection is most often performed through cervical esophagotomy or by proceeding directly to esophagectomy [3]; however, these approaches are associated with high morbidity and mortality rates. Very few excisions using an endoscopic approach have been reported in the literature, but the reported postoperative complications are lower [4].

- Video 1 shows the surgical steps in the transoral endoscopic surgical resection of a giant (23-cm) pedunculated polyp in a 43-year-old man ( $\bullet$ Fig. 1 ). The procedure was performed with the patient under general anesthesia. A flexible endoscope probe was used and the distal end of the polyp was extracted through the oral cavity with a loop. The Endo-GIA stapler (Covidien) was used to cut the base of polyp, which was then finally removed ( $\bullet$ Fig. 2). Histopathology confirmed the diagnosis of a fibrovascular polyp with no evidence of malignancy. The patient made an uneventful recovery and has had no recurrence after almost 3 years of follow up. This minimally invasive approach is a safe and feasible procedure to treat large esophageal fibrovascular polyps, avoiding the complications associated with more aggressive procedures.

\section{Endoscopy_UCTN_Code_TTT_1AO_2AG}

Competing interests: None

\section{Emilio Vicente ${ }^{1}$, Yolanda Quijano ${ }^{1}$, Benedetto lelpo ${ }^{1}$, Hipolito Duran', Eduardo Diaz ${ }^{1}$, Susana Prados ${ }^{2}$, Diego Juzgado ${ }^{3}$}

${ }^{1}$ General Surgery Department, Madrid Norte Sanchinarro San Pablo University Hospital, Madrid, Spain

2 Endoscopy Department, Madrid Norte Sanchinarro San Pablo University Hospital, Madrid, Spain

${ }^{3}$ Endoscopy Department, Quirón Salud, Pozuelo, Spain

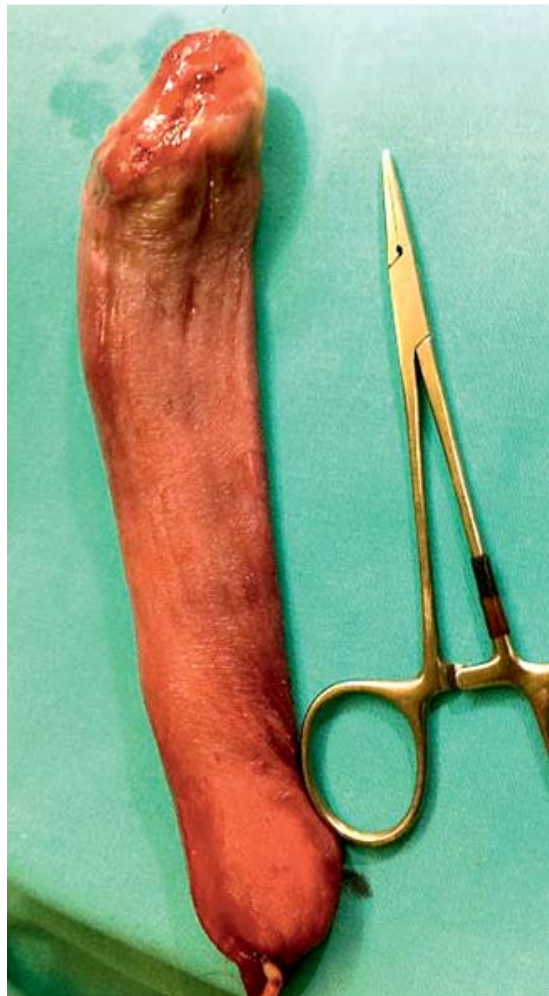

Fig.2 Macroscopic appearance of the resected specimen.

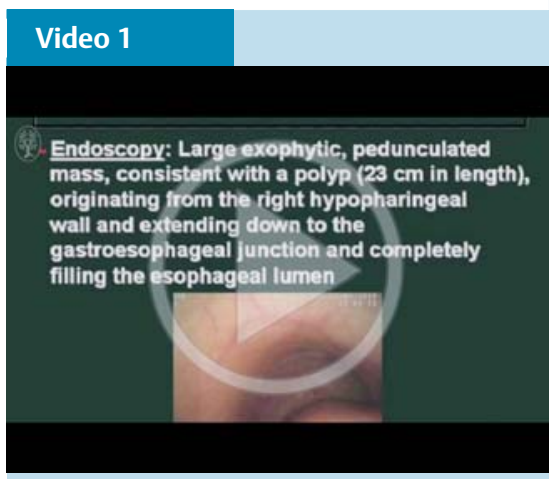

The surgical steps in transoral endoscopic surgical resection of a giant $(23-\mathrm{cm})$ pedunculated polyp. 


\section{References}

1 Levine MS, BuckJL, Pantongrag-Brown L et al. Fibrovascular polyps of the esophagus: clinical, radio-graphic, and pathologic findings in 16 patients. Am J Roentgenol 1996; 4: $781-787$

2 Sargent RL, Hood IC. Asphyxiation caused by giant fibrovascular polyp of the esophagus. Arch Pathol Lab Med 2006; 5: 725 - 727

3 Kanaan S, DeMeester TR. Fibrovascular polyp of the esophagus requiring esophagectomy. Dis Esophagus 2007; 5: 453 - 454

4 Pham AM, Rees CJ, Belafsky PC. Endoscopic removal of a giant fibrovascular polyp of the esophagus. Ann Otol Rhinol Laryngol 2008; 8: $587-590$

\section{Bibliography}

Dol http://dx.doi.org/

10.1055/s-0034-1393157

Endoscopy 2015; 47: E499-E500

(c) Georg Thieme Verlag KG

Stuttgart · New York

ISSN 0013-726X

\section{Corresponding author}

\section{Benedetto Ielpo, MD}

Madrid Norte Sanchinarro San Pablo University Hospital

General Surgery Department

Calle Oña 10

28050 Madrid

Spain

Fax: +34-91-7188733

ielpo.b@gmail.com 